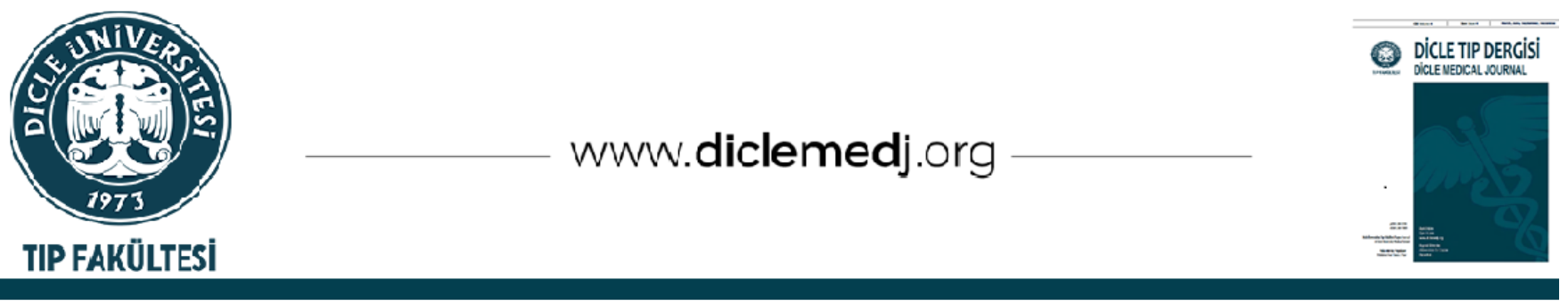

Özgün Araştırma / Original Article

\title{
Maraş Otunun Ağrı Şiddeti, Ağrı Eşiği ve Ağrı Toleransı Üzerine Etkisi
}

Nurten Seringeç Akkeçeci $\mathbb{D}_{1}$, Gözen öksüz $\mathbb{D}_{2}$

1 Kahramanmaraş Sütçü İmam Üniversitesi Tıp Fakültesi, Fizyoloji Anabilim Dalı, Kahramanmaraş, Türkiye

2 Kahramanmaraş Sütçü İmam Üniversitesi Tıp Fakültesi, Anesteziyoloji ve Reanimasyon Anabilim Dall, Kahramanmaraş, Türkiye

Geliş: 04.03.2021; Revizyon: 25.05.2021; Kabul Tarihi: 26.05.2021

\section{Öz}

Amaç: Bu çalışma, dumansız bir tütün formu olan maraş otunun kronik kullanımının ağrı şiddeti, ağrı eşiği ve ağrı toleransı üzerine herhangi bir etkisinin olup olmadığını belirlemek amacı ile planlanmıştır.

Yöntemler: Çalışmaya herhangi bir hastalığı bulunmayan 18-39 yaş arası, en az 5 yıldır maraş otu kullanan 10 kiși ve maraș otu ya da herhangi bir tütün ürünü kullanmayan 10 kişi olmak üzere toplam 20 sağlıklı erkek dahil edildi. Maraş otu kullanan kişilere deneylerden en az 12 saat önce maraş otu kullanmamaları söylendi. Maraş otu kullanan ve kullanmayan kişilerin ağrı şiddetleri, ağrı eşikleri ve ağrı toleransları karşılaştırıldı. Ağrı şiddeti vizüel analog skala (VAS) ile değerlendirildi. Ağrı eşiği ve ağrı toleransı soğuk pressör testi ile ölçüldü. Çalışmanın sonuçları Mann-Whitney U testi kullanılarak analiz edildi.

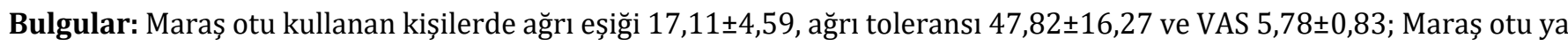
da herhangi bir tütün ürünü kullanmayan kişilerde ise ağrı eşiği 21,79 $\pm 6,11$, ağrı toleransı 72,82 $\pm 22,36$ ve VAS 3,78 $\pm 0,97$ olarak tespit edildi. Maraş otu kullanan kişilerin kullanmayanlara göre ağrı şiddeti (VAS) anlamlı olarak yüksek

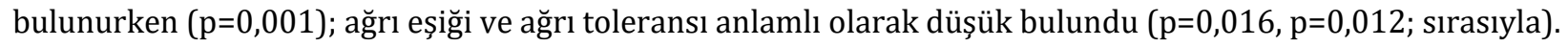

Sonuç: Bu çalışmadan elde edilen sonuçlar kronik maraş otu kullanan kişilerin kullanmayanlara göre hissettikleri ağrı şiddetinin daha yüksek olduğunu, ağrı eşiği ve ağrı toleranslarının ise daha düşük olduğunu göstermiştir. Dumansız tütün ürünlerinin ağrı üzerine etkilerini araştıran daha fazla çalışmaya ihtiyaç vardır.

Anahtar kelimeler: Maraş otu, Ağrı eşiği, Ağrı toleransı, Ağrı şiddeti, Vizüel analog skala (VAS)

DOI: 10.5798/dicletip.944402

Yazışma Adresi / Correspondence: Nurten Seringeç Akkeçeci, Kahramanmaraş Sütçü İmam Üniversitesi Tıp Fakültesi, Fizyoloji Anabilim Dalı, Bahçelievler Yerleşkesi 46100, Kahramanmaraș, Türkiye e-mail: seringec@hotmail.com 


\title{
The Effect of Maras Powder on Pain Intensity, Pain Threshold, and Pain Tolerance
}

\begin{abstract}
Objective: This study was planned to determine whether the chronic use of maras powder, a smokeless form of tobacco, has any effect on pain intensity, pain threshold, and pain tolerance.

Methods: A total of 20 healthy males without any illness and aged between 18-39 years were included in the study, including 10 people who had been using maras powder for at least 5 years, and 10 who had not used maras powder or any tobacco product. People using maras powder were told not to use maras powder at least 12 hours before the experiments. The pain intensity, pain thresholds, and pain tolerance of the people who used and did not use maras powder were compared. Pain intensity was evaluated with the visual analog scale (VAS). Pain threshold and pain tolerance were measured by the cold pressor test. The results of the study were analyzed using the Mann-Whitney U test.
\end{abstract}

Results: Pain threshold was $17.11 \pm 4.59$, pain tolerance was $47.82 \pm 16.27$ and VAS was $5.78 \pm 0.83$ in individuals using maras powder; Pain threshold was found as $21.79 \pm 6.11$, pain tolerance as $72.82 \pm 22.36$ and VAS $3.78 \pm 0.97$ in individuals who did not use maras powder or any tobacco product. While pain intensity (VAS) of people using maras powder was significantly higher than those who did not use it $(\mathrm{p}=0.001)$; their pain threshold and pain tolerance were found to be significantly lower than those who did not use it ( $p=0.016, p=0.012$; respectively).

Conclusion: The results obtained from this study showed that the pain intensity they felt of the people using chronically maras powder was higher than those who did not use it, and their pain threshold and pain tolerance were lower than those who did not use it. More studies are needed to investigate the effects of smokeless tobacco products on pain.

Keywords: Maras powder, Pain threshold, Pain tolerance, Pain severity, Visual analogue scale (VAS).

\section{GíRiş}

Maraş otu, Nicotiana rustica Linn bitkisinin kurutulmuş yapraklarından elde edilen toz ile meşe, ceviz, veya asma çubuğunun yakılmasıyla elde edilen külün eșit miktarda karıştırılması ile elde edilir ${ }^{1}$. Nicotiana rustica Linn'in nikotin içeriği, dünyada yaygın olarak kullanılan ve sigaranın ham maddesi olan Nicotiana tabacum'unkinden yaklaşık olarak 6-10 kat daha fazladır ${ }^{2}$. Maraş otu ilimizde yaygın olarak kullanılmaktadır.

Maraş otu, fiyatının ucuz olması sebebiyle sigaraya alternatif olarak tercih edilmekte ve kullanımı hakkında herhangi bir hukuksal sınırlama olmadığı için hemen hemen her yerde satılmaktadır. Bölgemizde Maraş otu kullananların sayısı zararları konusunda bilgi sahibi olmamaları ve sigaradan daha az zararlı olduğunu düşünmeleri nedeniyle her geçen gün artmaktadır.

Ağrl, gerçek veya potansiyel bir doku hasarından kaynaklanan hoş olmayan bir duyu ve duygusal bir deneyimdir. Ağrı eşiği, kişinin ağrı hissettiği en hafif uyaran şiddetidir. Ağrı toleransı ise bir kişinin dayanabileceği en yüksek ağrı derecesidir ${ }^{3,4}$.

Literatürde sigaranın ağrı eşiği ve ağrı toleransı üzerindeki etkilerini araştıran çalışmaların sonuçları çelişkilidir. Nastase ve ark. ${ }^{5}$ yaptıkları çalışmada sigara içen hem kadınların hem de erkeklerin ağrı eșiği ve ağrı toleranslarının sigara kullanmayan kadın ve erkeklere göre daha yüksek olduğunu rapor etmişlerdir. Tam tersine Bagot ve ark. ${ }^{6} 2017$ yılında yayınlanan çalışmalarında ise sigara kullanan kişilerin ağrı eşiği ve ağrı toleransını sigara kullanmayan kişilere göre daha düşük bulmuşlardır. Zhang ve ark. $^{7} 2020$ yılında yayınladıkları çalışmalarında ratlarda kısa süreli nikotin uygulamasının (1-3 hafta) mekanik eşiği artırdığını, ancak, uzun süreli nikotin maruziyeti (6-10 hafta) mekanik eşiği düşürdüğünü; nikotinin akut veya kısa süreli kullanıldığında analjezik görevi görürken, uzun süreli kronik nikotin kullanımının hiperaljezi ile sonuçlandığını bildirmişlerdir. Literatürde maraş otunun ağrı eşiği, ağrı toleransı ve ağrı şiddeti üzerine etkisini 
gösteren herhangi bir çalışma bulunmamaktadır.

$\mathrm{Bu}$ çalışma, kronik maraş otunun kullanımının ağrı şiddeti, ağrı eşiği ve ağrı toleransı üzerine herhangi bir etkisinin olup olmadığını belirlemek amacı ile planlanmıștır.

\section{YÖNTEMLER}

Çalışmaya maraş otu ya da herhangi bir tütün ürünü kullanmayan 10 kişi ve maraş otu kullanan (en az 5 yıldır) 10 kişi ve olmak üzere 18-39 yaş arası toplam 20 sağlıklı erkek denek dahil edildi. 18 yaș altı olan veya hikayesinde geçirilmiş veya var olan akciğer hastalığı, koroner kalp hastalığı ve kalp yetmezliği, romatizmal kalp hastalığı, dolaşım hastalığı, diyabet, epilepsi, veya diğer herhangi bir sistemik hastalığ enfeksiyon geçirmiş olanlar ve herhangi bir ilaç kullananlar çalışma dıșı bırakıldı. Maraş otu kullanan kişilere deneylerden en az 12 saat önce maraş otu kullanmamaları söylendi.

Çalışmaya başlamadan önce KSÜ Tıp Fakültesi Klinik Araștırmalar Etik Kurulu'ndan onay alındı (2018/05: Karar No: 30, 28.02.2018). Çalışma "Helsinki Deklarasyonu ilkeleri" ne uygun olarak yapıldı. Tüm katılımcılardan yazılı bilgilendirilmiş onam alındı.

Ağrı eşiği ve ağrı toleransı ölçümü soğuk pressör testi (cold pressure test) kullanılarak yapıldı. Kişilerin eli bileğe kadar $4^{\circ} \mathrm{C}$ 'de buz kovasına batırtıldı. Ağrıyı ilk hissettikleri anda haber vermeleri istendi. Deneklerin ellerini buz kovasına daldırdıkları anda kronometre başlatıldı ve ağrı hissettim dedikleri andaki zaman ağrı eşiği olarak kaydedildi. Ağrı toleransı ölçümü için deneklere ellerini mümkün olduğunca suda tutmaları ve dayanamadıkları anda bildirip kovadan çıkarmaları söylendi. Deneğin elini buz kovasına daldırdıktan çıkartana kadar geçen süre ağrı toleransı olarak kaydedildi.
Deneklerin ağrı șiddeti soğuk pressör testinden hemen sonra vizüel analog skala (VAS) (0-hiç ağrı yok; 10 çok şiddetli ağrı var) ile değerlendirildi.

Deneylerden elde edilecek sonuçların değerlendirilmesinde "SPSS 15.0 for Windows" istatistik paket programı kullanıldı. Gruplar karşılaştırılırken "Mann-Whitney U Testi" kullanıldı. İstatistiksel anlamlılık değerlendirmesi için p değeri 0,05 olarak seçildi. Test sonuçları $\mathrm{p}<0,05$ ise anlamlı kabul edildi.

\section{BULGULAR}

Maraş otu kullanan gruba ve kontrol grubuna ait veriler Tablo I'de verilmiștir. Yaș, boy, kilo, vücut kitle indeksi (VKİ) gibi demografik özellikler bakımdan gruplar arasında fark yoktu ( $p=0,094, p=0,106, p=0,468, p=0,952$; sırasıyla; Tablo I). Maraş otu kullanan grupta kullanım

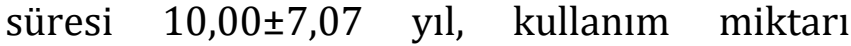
13,33 $\pm 4,85$ adet/gün olarak bulunmuştur.

Ağrl eşiği, maraş otu kullanan grupta $17,11 \pm 4,59$, kontrol grubunda ise $21,79 \pm 6,11$ idi. Maraş otu kullanan kişilerin ağrı eşiği maraş otu kullanmayan sağlıklı kontrollere göre anlamlı olarak düşük bulundu ( $\mathrm{p}=0,016$; Tablo I).

Ağrı toleransı, maraș otu kullanan grupta $47,82 \pm 16,27$, kontrol grubunda ise $72,82 \pm 22,36$ idi. Maraş otu kullanan kişilerin ağrı toleransı maraş otu kullanmayan sağlıklı kontrollere göre anlamlı olarak düşük bulundu ( $\mathrm{p}=0,012$; Tablo I).

Ağrı şiddeti (VAS değeri), maraş otu kullanan grupta 5,78 $\pm 0,83$, kontrol grubunda ise $3,78 \pm 0,97$ idi. Maraş otu kullanan kişilerin ağrı şiddeti maraş otu kullanmayan sağlıklı kontrollere göre anlamlı olarak yüksek bulundu $(p=0,001$; Tablo I). 
Tablo I: Maraş otu kullanan ve kontrol gruplarının demografik özellikleri, ağrı eşiği, ağrı toleransı ve ağrı şiddeti değerleri

\begin{tabular}{|l|l|l|l|}
\hline & Maraş otu & Kontrol & $P$ \\
\hline Yaș (yıl) & $30,33 \pm 7,22$ & $25,56 \pm 4,83$ & 0,094 \\
\hline Boy (m) & $1,79 \pm 0,05$ & $1,75 \pm 0,06$ & 0,106 \\
\hline Kilo (kg) & $75,33 \pm 13,65$ & $71,13 \pm 8,80$ & 0,468 \\
\hline VKİ & $23,38 \pm 3,60$ & $23,49 \pm 3,82$ & 0,952 \\
\hline Ağrı eşiği & $17,11 \pm 4,59$ & $21,79 \pm 6,11$ & $\mathbf{0 , 0 1 6}$ \\
\hline Ăgrı & $47,82 \pm 16,27$ & $72,82 \pm 22,36$ & $\mathbf{0 , 0 1 2}$ \\
toleransı & & & \\
\hline VAS & $5,78 \pm 0,83$ & $3,78 \pm 0,97$ & $\mathbf{0 , 0 0 1}$ \\
\hline
\end{tabular}

VAS: Vizüel analog skala; VKí: Vücut kitle indeksi

\section{TARTIŞMA}

$\mathrm{Bu}$ çalışma uzun süredir kronik olarak maraş otu kullanan kişilerde ağrı eșiği, ağrı toleransı ve ağrı şiddetini değerlendiren ilk çalışmadır. Kronik olarak maraş otu kullanan kişilerde ağrı eşiği, ağrı toleransı ve ağrı şiddeti değerlerini değerlendirdiğimiz çalışmamızın sonucunda; kronik olarak maraş otu kullanan kişilerin kullanmayanlara göre hissettikleri ağrı şiddetinin daha yüksek olduğunu; ağrı eșiği ve ağrı toleranslarının ise daha düşük olduğunu tespit ettik.

Nikotinin analjezik etkiye sahip olduğu pek çok hayvan ve insan çalışmasında gösterilmiştir8-11. Nikotinin analjezik etkileri santral ve periferik nikotinik asetilkolin reseptörlerindeki (nAChR) etkileri sonucu ortaya çıkmaktadır ${ }^{12-14}$. Nikotinin antinosiseptif etkileris-11 var gibi görünse de, birçok çalışmada da sigara içenlerin hissettikleri ağrı şiddetinin daha yüksek olduğu ve daha yüksek kronik ağrı insidansı gösterdikleri öne sürülmüştür 15-17. Ayrıca, kronik ağrı bozukluğu olan sigara içenler ve içmeyenler arasında karşılaştırma yapan bir çalışmada da sigara içenlerin hissettikleri ağrı şiddetinin daha yüksek olduğu ve içmeyenlere göre daha yüksek VAS değerlerine sahip olduğu gösterilmiştir ${ }^{18}$. Kim ve ark. yaptıkları çalışmada sigara içenlerde nikotine bağlı analjeziye tolerans gelişiminin sigara içenlerin ağrı algısını artırdığını ve sigara içenlerin içmeyenlere göre günlük içtikleri sigara miktarına bakılmaksızın ameliyat sonrası daha fazla opioid kullanımına ihtiyaç duyduklarını göstermişlerdir ${ }^{19}$. Biz de çalışmamızda yüksek miktarda nikotin içeren dumansız bir tütün formu olan maraş otu kullanan kişilerin hissettikleri ağrı şiddetinin ve VAS değerlerinin kullanmayan kişilere göre daha yüksek olduğunu bulduk.

Literatürde sigaranın ağrı eşiği ve ağrı toleransı üzerindeki etkilerini araştıran çalışmaların sonuçları çelişkilidir. Nastase ve ark. ${ }^{5}$ soğuk pressör testi ile ağrı eşiği ve ağrı toleransını değerlendirdikleri çalışmalarının sonucunda sigara içen hem kadınların hem de erkeklerin ağrı eşiği ve ağrı toleranslarının sigara kullanmayan kadın ve erkeklere göre daha yüksek olduğunu rapor etmişlerdir. Tam tersine Bagot ve ark. $^{6} 2017$ yllında yayınlanan çalışmalarında ise sigara kullanan kişilerin ağrı eşiği ve ağrı toleransını soğuk pressör testi ile ölçmüşler ve sigara kullanmayan kişilere göre daha düşük bulmuşlardır. Biz de çalışmamızda uzun süredir maraş otu kullanan kişilerin kullanmayan kişilere göre soğuk pressör testi ile ölçmüş olduğumuz ağrı eşiklerinin ve ağrı toleranslarının daha düşük olduğunu bulduk.

Akut nikotin kullanımı analjezik etki gösterirken, ${ }^{20}$ nikotin ve tütün dumanına kronik olarak maruz kalmanın zamanla ağrıya duyarlllığı artırabileceği öne sürülmüştürr ${ }^{21,22}$. Zhang ve ark. ${ }^{7} 2020$ yılında yayınladıkları çalışmalarında ratlarda kısa süreli nikotin uygulamasının (1-3 hafta) mekanik eşiği artırdığını, ancak, uzun süreli nikotin maruziyeti (6-10 hafta) mekanik eşiği düşürdügünü; nikotinin akut veya kısa süreli kullanıldığında analjezik görevi görürken, uzun süreli kronik nikotin kullanımının hiperaljezi ile 
sonuçlandığını bildirmişlerdir. Dahası, kısa süreli nikotin maruziyetinde glutamat dekarboksilaz 67 (GAD67) ve glutamat dekarboksilaz 65 (GAD65) ekspresyonundaki artışlara bağlı olarak $\gamma$-aminobütirik asitin (GABA) salgılanmasının arttığını ve endojen $\mu$ opioid reseptörünün (MOR) yukarı doğru düzenlediğini, GABA ve endojen opioidlerin nikotine bağlı hiposensitivitede rol oynadığını; tam tersi uzun süreli nikotin maruziyetinde ise GAD67 ekspresyonundaki azalışa bağlı olarak GABA'nın salgılanmasının azaldığını, MOR ekspresyonunun azaldığını ve gözlemlenen hiperaljezinin GABA'daki azalmadan kaynaklandığını öne sürmüşler ve nikotinin, GAD65, GAD67, MOR, endorfin ve GABA ekspresyonunu etkileyerek ağrı duyarlılığını değiștiriyor olabileceğini bildirmişlerdir. Biz de çalışmamızda uzun süredir maraş otu kullanan kişilerin kullanmayan kişilere göre ağrı eşiklerinin daha düşük olduğunu bulduk.

Çalışmamızın en önemli sınırlaması örneklem büyüklüğünün küçük olmasıdır. Ayrıca akut maraş otu kullanımının etkileri çalışmamızda değerlendirilmemiștir. Maraş otu ve diğer dumansız tütün ürünlerinin akut ve kronik kullanımının ağrı üzerine etkilerini araştıran daha fazla çalışmaya ihtiyaç vardır.

\section{SONUÇ}

$\mathrm{Bu}$ çalışmadan elde edilen sonuçlar kronik maraş otu kullanan kişilerin kullanmayanlara göre hissettikleri ağrı şiddetinin daha yüksek olduğunu, ağrı eşiği ve ağrı toleranslarının ise daha düşük olduğunu göstermiştir. Dumansız tütün ürünlerinin ağrı üzerine etkilerini araştıran daha fazla çalışmaya ihtiyaç vardır.

Bu çalışma 1st International Health Science And Life Congress (IHSLC 2018) (02-05 MAY 2018 / BURDUR-TURKIYE) sözlü bildiri olarak sunulmuş ve özeti kongre kitabında yayınlanmıştır.

Etik Kurul Kararı: Çalışmaya başlamadan önce KSÜ Tıp Fakültesi Klinik Araştırmalar Etik
Kurulu'ndan onay alındı (2018/05: Karar No: 30, 28.02.2018). Çalışma "Helsinki Deklarasyonu ilkeleri" ne uygun olarak yapıldı. Tüm katılımcılardan yazılı bilgilendirilmiş onam alındı.

Çıkar Çatışması Beyanı: Yazarlar çıkar çatışması olmadığını bildirmişlerdir.

Finansal Destek: Bu çalışma her hangi bir fon tarafından desteklenmemiştir.

Declaration of Conflicting Interests: The authors declare that they have no conflict of interest.

Financial Disclosure: No financial support was received.

\section{KAYNAKLAR}

1. Köse E, Yazıcıoğlu Moçin Ö, Çelik H, Gencer M. Dumansız Tütün "Maraş Otu" Kullanımına Bağlı Artmış Oksidatif Stres. Tur Toraks Der. 2011; 12: 949.

2. Saitoh F, Noma M, Kawashima N. The alkaloid contents of sixty nicotine species. Phytochemistry. 1985; 24: 477-80.

3. Merskey H, Bogduk N. Classification of chronic pain. 2nd edn. Seattle: IASP Press; 1994: 207-13.

4. Tütüncü R, Günay H. Chronic pain, psychological factors and depression. Dicle Med J. 2011; 38: 25762.

5. Nastase A, Ioan S, Braga RI, Zagrean L, Moldovan M. Coffee drinking enhances the analgesic effect of cigarette smoking. Neuroreport. 2007; 18: 921-4.

6. Bagot KS, Wu R, Cavallo D, Krishnan-Sarin S. Assessment of pain in adolescents: Influence of gender, smoking status and tobacco abstinence. Addict Behav. 2017; 67: 79-85.

7. Zhang Y, Yang J, Sevilla A, et al. The mechanism of chronic nicotine exposure and nicotine withdrawal on pain perception in an animal model. Neurosci Lett. 2020; 715: 134627.

8. Aceto MD, Awaya H, Martin BR, May EL. Antinociceptive action of nicotine and its methiodide derivatives in mice and rats. $\mathrm{Br} \mathrm{J}$ Pharmacol. 1983; 79: 869-76. 
9. Phan DV, Dóda M, Bite A, György L Antinociceptive activity of nicotine. Acta Physiol Acad Sci Hung. 1973; 44: 85-93.

10. Waller D, Schalling D, Levander S, Edman G. Smoking, pain tolerance, and physiological activation. Psychopharmacology (Berl). 1983; 79: 193-8.

11. Kanarek RB, Carrington C. Sucrose consumption enhances the analgesic effects of cigarette smoking in male and female smokers. Psychopharmacology (Berl). 2004; 173: 57-63.

12. Tripathi HL, Martin BR, Aceto MD. Nicotineinduced antinociception in rats and mice: Correlation with nicotine brain levels. J Pharmacol Exp Ther. 1982; 221: 91-6.

13. Marubio LM, del Mar Arroyo-Jimenez M, Cordero-Erausquin $\mathrm{M}$, et al. Reduced antinociception in mice lacking neuronal nicotinic receptor subunits. Nature. 1999; 398: 805-10.

14. Rao TS, Correa LD, Reid RT, Lloyd GK. Evaluation of anti-nociceptive effects of neuronal nicotinic acetylcholine receptor (NAChR) ligands in the rat tail-flick assay. Neuropharmacology. 1996; 35: 393405.

15. Andersson H, Ejlertsson G, Leden I. Widespread musculoskeletal chronic pain associated with smoking. An epidemiological study in a general rural population. Scand J Rehabil Med. 1998; 30: 185-91.

16. Weingarten TN, Iverson BC, Shi Y, et al. Impact of tobacco use on the symptoms of painful temporomandibular joint disorders. Pain. 2009; 147: 67-71.

17. Weingarten TN, Podduturu VR, Hooten WM, et al. Impact of tobacco use in patients presenting to a multidisciplinary outpatient treatment program for fibromyalgia. Clin J Pain. 2009; 25: 39-43.

18. Weingarten TN, Moeschler SM, Ptaszynski AE, et al. An assessment of the association between smoking status, pain intensity, and functional interference in patients with chronic pain. Pain Physician. 2008; 11: 643-53.

19. Kim DH, Park JY, Karm MH, et al. Smoking May Increase Postoperative Opioid Consumption in Patients Who Underwent Distal Gastrectomy With Gastroduodenostomy for Early Stomach Cancer: A Retrospective Analysis. Clin J Pain. 2017; 33: 905-11.

20. Ditre JW, Heckman BW, Zale EL, Kosiba JD, Maisto SA. Acute analgesic effects of nicotine and tobacco in humans: a meta-analysis. Pain. 2016; 157: 1373-81.

21. Ditre JW, Brandon TH, Zale EL, Meagher MM. Pain, nicotine, and smoking: Research findings and mechanistic considerations. Psychol Bull. 2011; 137: 1065-93.

22. Shi Y, Weingarten TN, Mantilla CB, Hooten WM, Warner DO. Smoking and pain: Pathophysiology and clinical implications. Anesthesiology. 2010; 113: 977-92. 